\title{
Antioxidant activity of phlorotannins from brown algae
}

\author{
Xin Liu ${ }^{1}$, Wenqiao Yuan ${ }^{1 *}$, Ratna Sharma-Shivappa ${ }^{1}$, John van Zanten ${ }^{2}$ \\ (1. Department of Biological and Agricultural Engineering, North Carolina State University, Raleigh, NC 27695, USA; \\ 2. Golden LEAF Biomanufacturing Training \& Education Center, North Carolina State University, Raleigh, NC 27695, USA)
}

\begin{abstract}
The antioxidant activity of the phlorotannins extracted from five marine algae species (Saccharina latissima, Alaria esculenta, Laminaria digitata, Fucus vesiculosus and Ascophyllum nodosum) was studied. Three phlorotannin groups, including soluble, membrane-bound, and extracted membrane-bound phlorotannins obtained by two solvent extraction methods were investigated for their DPPH radical scavenging activity. F. vesiculosus and A. nodosum showed the highest phlorotannin yield (14.83 mg-extract/g-algae and $12.80 \mathrm{mg}$-extract/g-algae, respectively) among the five algae species. Their soluble phlorophannin (SP), membrane-bound phlorotannin (MP) and extracted membrane-bound phlorotannin (eMP) extracts all showed equal or greater DPPH radical scavenging activity than the commercial antioxidants of butylated hydroxytoluene and ascorbic acid. The antioxidant potential that combines phlorotannin yield and antioxidant activity of the MP extracts of $F$. vesiculosus and A. nodosum (5890 $\mathrm{mL} / \mathrm{g}$ and $5278 \mathrm{~mL} / \mathrm{g}$ algae, respectively) were higher than those of SP and eMP, suggesting that the MPs of $F$. vesiculosus and A. nodosum had great potential to be used as antioxidants. Different extraction methods also showed significantly different effects on the antioxidant activity of the phlorotannin extracts.
\end{abstract}

Keywords: brown algae, phlorotannin, antioxidant activity, antioxidant, bioseparation, polyphenol, solvent extraction methods DOI: $10.25165 /$ j.ijabe.20171006.2854

Citation: Liu X, Yuan W Q, Sharma-Shivappa R, van Zanten J. Antioxidant activity of phlorotannins from brown algae. Int J Agric \& Biol Eng, 2017; 10(6): 184-191.

\section{Introduction}

Reactive Oxygen Species (ROS) are the major causes of oxidative damage and related diseases such as atherosclerosis, rheumatoid arthritis, muscular dystrophy, cataracts, some neurological disorders and some types of cancer as well as aging. ROS are a class of highly reactive molecules formed during aerobic life ${ }^{[1]}$. Normal levels of ROS may be essential for many cellular functions such as killing phagocytes, bacterial ingestion and redox regulation of signal transduction. However, overproduction of ROS in living organisms can cause

Received date: 2016-09-15 Accepted date: 2017-02-06

Biographies: Xin Liu, PhD student, research interest: bioproducts, Email: xliu30@ncsu.edu; Ratna Sharma-Shivappa, Associate Professor, research interest: biofuels, Email: rsharm2@ncsu.edu; John van Zanten, Assistant Teaching Professor, research interest: biotechnology, Email: john_vz@ncsu.edu.

*Corresponding author: Wenqiao Yuan, Professor, research interests: biofuels and bioproducts, 265 Weaver Labs, North Carolina State University. Tel: +1 919-515-6742, Fax: +1 919515-7760, Email: wyuan2@ncsu.edu. harm to DNA, cell membrane, proteins and consequently induce degeneration, destruction and toxicity of various molecules in cells ${ }^{[2]}$.

Natural antioxidants in terrestrial plants and their applications in food preservation and nutraceuticals have been studied in numerous cases. Some synthetic antioxidants like butylated hydroxyanisol (BHA), butylated hydroxytoluene (BHT), tertiary butyl hydroquinone and propyl gallate have been applied in food, cosmetic and drug products ${ }^{[3]}$. However, the side effects and toxicity of these synthetic antioxidants have been questioned and researchers are looking for natural antioxidants that can be safely used in food and medicine ${ }^{[4]}$. Polyphenols are the most abundant dietary antioxidants by scavenging free radicals and inhibition of the generation of ROS during cell metabolism ${ }^{[5]}$. Phlorotannins in brown algae are prominent natural antioxidants that may replace synthetic antioxidants. Some phlorotannins isolated from edible brown algae have shown stronger antioxidant activity than commercial antioxidants $^{[5,6]}$. 
Phlorotannins are the polyphenolic compounds that are only found in marine brown macroalgae. They consist of polymers of phloroglucinol (1,3,5-tryhydroxybenzene) units that are formed in the acetate-melonate pathway as secondary metabolites. They are highly hydrophilic compounds with a wide range of molecular sizes from $400 \mathrm{Da}$ to $400000 \mathrm{Da}$ and occur in variable contents (0.5\%-20\%) in brown algae. They have been reported to have pharmaceutical activities such as antibacterial, antioxidant, antifungal, anti-HIV, anti-diabetes, anti-inflammation and anti-allergic functions ${ }^{[7]}$. Phlorotannins can be divided into two groups, soluble phlorotannins (SPs) and membrane-bound phlorotannins (MPs), according to their location in brown algae cells. SPs are stored in cell organelles, physodes, which are round or elliptical, highly mobile, vesicle-like, strongly refractive bodies in the cytoplasm of brown algae cells. MPs are believed to transform into components of cell walls when physodes fuse with cell membrane and the phlorotannins are secreted into the cell wall, complexing finally with alginic $\operatorname{acid}^{[8]}$.

To the best knowledge of the authors, the antioxidant activity of MP and eMP extracts has not been studied. Radical scavenging activity of the SP has been reported in some articles but the five algae species, Saccharina latissima (kelp), Alaria esculenta (alaria), Laminaria digitata (digitata), Fucus vesiculosus (bladderwrack) and Ascophyllum nodosum (rockweed) have not been fully investigated. Furthermore, the effects of different extraction processes on the antioxidant activity of the phlorotannin extracts were not fully studied. Thus the objectives of this study were to evaluate the antioxidant activity of soluble and membrane-bound phlorotannins of S. latissima, A. esculenta, L. digitata, $F$. vesiculosus and A. nodosum, and examine the influence of two commonly used solvent extraction methods on the antioxidant activity of the phlorotannin extracts.

\section{Materials and methods}

\subsection{Materials}

Five brown algae $S$. latissima (kelp), A. esculenta (alaria), L. digitata (digitata), $F$. vesiculosus (bladderwrack) and A. nodosum (rockweed) were obtained from Maine Coast Sea Vegetables (Franklin, ME, USA), all in dried powder except for S. latissima which was in dried whole leaf. The samples were sealed in airtight bags and had a greenish brown color. The whole leaf of S. latissima was ground and sieved with a 1-mm sieve before extraction. All samples were sealed and stored under $-20^{\circ} \mathrm{C}$ until experiments.

\subsection{Methods}

\subsubsection{Phlorotannin extraction and sample preparation}

The SP was extracted with two solvent extraction methods commonly found in the literature. The extraction processes are shown in Figures 1 and 2. In the first extraction method (designated as Method 1), methanol $(\mathrm{MeOH})$, chloroform $\left(\mathrm{CHCl}_{3}\right)$, deionized water and ethyl acetate (EtOAc) were applied in sequence ${ }^{[9-11]}$. In the second extraction method (designated as Method 2), $\mathrm{MeOH}$, dichloromethane $\left(\mathrm{CH}_{2} \mathrm{Cl}_{2}\right)$, EtOAc, and $n$-butanol were used ${ }^{[12-14]}$. The EtOAc fraction in both extraction methods contained phlorotannins and was analyzed for TPC and DPPH radical scavenging activity. Algae species with high phlorotannin content and antioxidant activity by Method 1 were also extracted by Method 2 .

Algae powder residue from solvent extraction was extracted with the method of Budhiyanti et al. ${ }^{[8]}$ to obtain the MP. Firstly, $200 \mathrm{mg}$ algae residue after SP extraction was dissolved in $8 \mathrm{~mL} 1 \mathrm{M} \mathrm{NaOH}$, stirred for 2 $\mathrm{h}$, and concentrated under $2400 \mathrm{~g}$ for $5 \mathrm{~min}$. Then, the supernatant was neutralized with phosphoric acid and its MP content was tested.

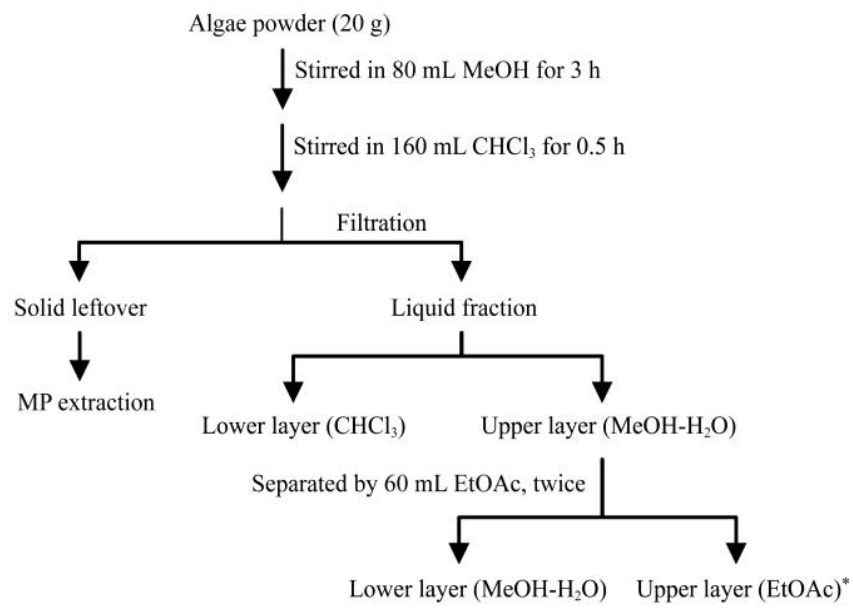

Note: *represents the fraction containing phlorotannin ${ }^{[9-11]}$

Figure 1 First extraction method for SP extraction 
Algae powder $(20 \mathrm{~g})$

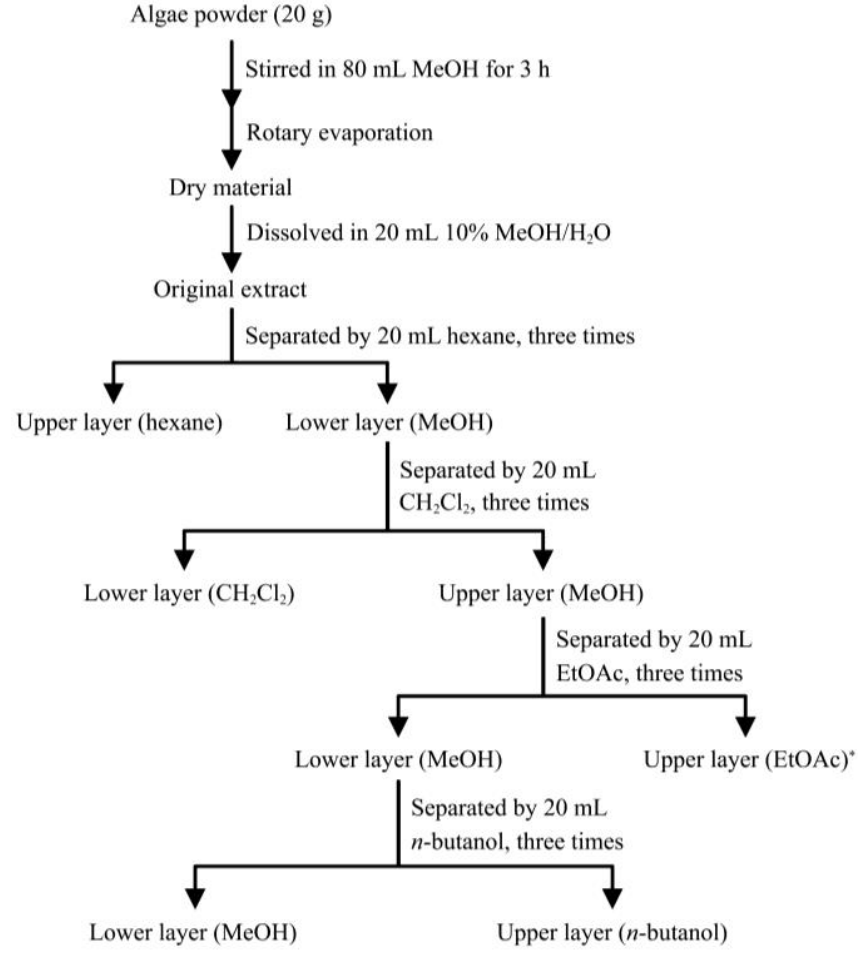

Note: *represents fraction containing phlorotannin ${ }^{[12-14]}$

Figure 2 Second extraction method for SP extraction

The eMP extracts were obtained by extracting the MP extracts with a modified version of the first extraction method, in which ethyl ether was applied in place of ethyl acetate $^{[15]}$. The liquid fractions containing phlorotannins obtained by these processes were evaporated with rotary evaporator and dried in vacuum under $60^{\circ} \mathrm{C}$ for $24 \mathrm{~h}$ to obtain the dried extracts of phlorotannins. The mass of dried extracts were measured to evaluate the yields of phlorotannin extracts. All samples were freshly prepared and tested within $24 \mathrm{~h}$. All chemicals and organic solvents were of analytical grade and purchased from Fisher Scientific (Pittsburgh, PA, USA).

\subsubsection{DPPH radical scavenging activity test}

The 2,2-diphenyl-1-picrylhydrazyl (DPPH) radicals are stable organic nitrogen radicals bearing a deep purple color $^{[16]}$. They may be neutralized by either direct reduction via single electron transfer or by radical quenching via hydrogen atom transfer. During reactions, color of the solution changes from purple to yellow when the antioxidants eliminate the DPPH radicals ${ }^{[17]}$. The DPPH assay has been widely used due to its stability, simplicity, rapidity and reproducibility. The other reason for applying DPPH test is that both phlorotannins and DPPH radicals are easily dissolved in methanol, which is the reaction condition for DPPH assay. The most widely used parameter evaluating the property of scavenging DPPH radicals is the $\mathrm{IC}_{50}$ value, which is the phlorotannin amount that can eliminate half of given DPPH radicals ${ }^{[18,19]}$. The extracts with lower $\mathrm{IC}_{50}$ value indicate stronger antioxidant activity.

DPPH free radical scavenging activity was measured using the method of Cox et al. ${ }^{[20]}$ with minor modifications. A $1 \mathrm{mg} / \mathrm{mL}$ phlorotannin solution was made by dissolving dried phlorotannin extracts in deionized water. Then the solution was diluted with deionized water by $10,100,1000$ and 10000 times to make a series of phlorotannin samples with various concentrations. A $152 \mu \mathrm{M}$ DPPH radical solution was made by dissolving DPPH radicals in methanol. Then $0.1 \mathrm{~mL}$ phlorotannin sample was added to $0.1 \mathrm{~mL}$ of $152 \mu \mathrm{M}$ DPPH radical solution. The reaction mixtures were incubated in the dark for $30 \mathrm{~min}$ at room temperature, and the optical density (OD) was measured at $517 \mathrm{~nm}$ using a BioTek 96-well microplate reader (Winooski, VT, USA). The DPPH test was performed in triplicate and the result was expressed as half maximum inhibitory concentration $\left(\mathrm{IC}_{50}\right)$ value (mg-extract/mL-water), which was the phlorotannin concentration whose radical scavenging capacity was $50 \%$. The ability to scavenge the DPPH radical was calculated with the following equations:

$$
\text { Scavenging capacity }=1-\frac{A_{\text {sample }}-A_{\text {sampleblank }}}{A_{\text {control }}}
$$

where, $A_{\text {control }}$ is the OD of the DPPH solution; $A_{\text {sample }}$ is the OD of DPPH solution with sample; $A_{\text {sampleblank }}$ is the OD value of the sample only. The DPPH radicals were purchased from Sigma-Aldrich CO. LLC. (St. Louis, MO, USA). Commercial antioxidants BHT and ascorbic acid were purchased from Fisher Scientific and their antioxidant activities were also measured for comparison purpose.

\subsubsection{Total phlorotannin content test}

The total phlorotannin content (TPC) was determined according to a modified version of Folin-Ciocalteu method, using phloroglucinol (PHG) as the standard ${ }^{[20]}$. Samples were diluted taking into account the range of the standard curve. A $0.04 \mathrm{~mL}$ aliquot of the sample was mixed in a $1.5 \mathrm{~mL}$ centrifugation tube with $0.4 \mathrm{~mL} 1 \mathrm{~N}$ 
Folin-Ciocalteu reagent and $0.8 \mathrm{~mL} 20 \% \mathrm{Na}_{2} \mathrm{CO}_{3}$. After standing for $3 \mathrm{~min}$, the sample was incubated in the dark at room temperature for $45 \mathrm{~min}$ and centrifuged at $1600 \mathrm{~g}$ for $8 \mathrm{~min}$. Optical density (OD) of the supernatant was measured at $730 \mathrm{~nm}$ using a BioTek 96-well microplate reader (Winooski, VT, USA). TPC test was performed in triplicate and the result was expressed as mg phloroglucinol equivalent per gram algae (mg PHG/g algae) using the following calibration equation: $Y=2.3356 X-0.0544\left(r^{2}=0.996\right)$, where $Y$ is the OD at $730 \mathrm{~nm}$ and $X$ is the concentration of phloroglucinol as the standard $(\mathrm{mg} / \mathrm{mL})$. Folin-Ciocalteu phenolic reagent and phloroglucinol were obtained from Sigma-Aldrich CO. LLC. All other chemicals and organic solvents were obtained from Fisher Scientific.

\subsubsection{Statistical analysis}

The results of the present study were expressed as mean \pm standard deviation. Statistical analysis was performed by one-way ANOVA and Tukey test with SAS (Cary, NC, USA). A $p$-value of 0.05 or less was considered significant.

\section{Results and discussion}

\subsection{DPPH scavenging activity of SP}

The DPPH scavenging activity, expressed as $\mathrm{IC}_{50}$ value, is shown in Table 1. A. nodosum and F. vesiculosus had the strongest DPPH scavenging activity among the SP extracts of the five algae species by Method 1 . Meanwhile, significant differences in antioxidant activity were observed between the two extraction methods for $A$. nodosum and $F$. vesiculosus. Method 1 was better on $F$. vesiculosus while Method 2 was better on A. nodosum in terms of antioxidant activity of SP. It indicated that extraction process had effects on the antioxidant activity of the extracts obtained, which agreed with the results of Turkmen et al. ${ }^{[21]}$, who reported that the antioxidant activity of black tea extracts were dependent on the solvent used and length of the extraction processes. The $\mathrm{IC}_{50}$ value of $S$. latissima $(0.62 \pm 0.06 \mathrm{mg} / \mathrm{mL})$ was significantly lower than L. digitata $(0.74 \pm 0.10 \mathrm{mg} / \mathrm{mL})$. It suggested that the SP extract of S. litissima was a better antioxidant than L. digitata. However, Cox et al. ${ }^{[20]}$ reported that the $\mathrm{IC}_{50}$ value of $\mathrm{SP}$ from $L$. digitata was much lower than $S$. latissima. A study investigating the DPPH radical scavenging activity of extracts from brown algae Sargassum marginatum, Padina tetrastomatica and Turbinaria conoides, used a method that was similar to the present study ${ }^{[22]}$. The $\mathrm{IC}_{50}$ values reported in their study were higher than those of $A$. nodosum and $F$. vesiculosus investigated in the present study, which suggested that $A$. nodosum and $F$. vesiculosus could be better sources of antioxidants than $S$. marginatum, $P$. tetrastomatica and $T$. conoides. The DPPH radical scavenging activity of SP extracts from the two algae

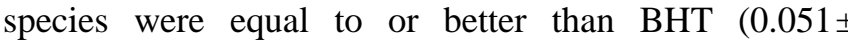
$0.0005 \mathrm{mg} / \mathrm{mL})$ and ascorbic acid $(0.0063 \pm 0.0002 \mathrm{mg} / \mathrm{mL})$.

Table 1 DPPH radical scavenging activity of the SP extracts from the two extraction methods

\begin{tabular}{lcc}
\hline \multicolumn{1}{c}{ Algae species } & $\begin{array}{c}\mathrm{IC}_{50} \text { value of Method 1 } \\
/ \mathrm{mg} \cdot \mathrm{mL}^{-1}\end{array}$ & $\begin{array}{c}\mathrm{IC}_{50} \text { value of Method 2 } \\
/ \mathrm{mg} \cdot \mathrm{mL}^{-1}\end{array}$ \\
\hline Ascophyllum nodosum & $0.0072 \pm 0.0010 \mathrm{~d}, \mathrm{p}$ & $0.0063 \pm 0.0004 \mathrm{q}$ \\
Fucus vesiculosus & $0.0038 \pm 0.0002 \mathrm{~d}, \mathrm{~s}$ & $0.0077 \pm 0.0001 \mathrm{r}$ \\
Laminaria digitata & $0.74 \pm 0.01 \mathrm{a}$ & \\
Alaria esculenta & $0.09 \pm 0.00 \mathrm{c}$ & \\
Saccharina latissima & $0.62 \pm 0.06 \mathrm{~b}$ & \\
\hline
\end{tabular}

Note: The letters a, b, c, d indicate significant difference among the SP of the five algae species obtained by Method $1(\mathrm{a}>\mathrm{b}>\mathrm{c}>\mathrm{d})$; Letters $\mathrm{p}$ and $\mathrm{q}$ indicate significant difference between the SP of Ascophyllum nodosum obtained by the two extraction methods ( $\mathrm{p}>\mathrm{q})$; Letters $\mathrm{r}$ and $\mathrm{s}$ indicate significant difference between the SP of Fucus vesiculosus obtained from the two extraction methods $(\mathrm{r}>\mathrm{s})$. A $p$-value of 0.05 or less was considered to indicate significant difference.

The correlation between $\mathrm{TPC}$ and $\mathrm{IC}_{50}$ values of the SP extracts obtained by the first extraction method is shown in Figure 3. A strong correlation coefficient $\left(r^{2}=\right.$ 0.98) was observed among the four algae species $A$. nodosum, F. vesiculosus, S. latissima and L. digitata, suggesting the algae species with higher SP content also had stronger antioxidant activities. Interestingly, when A. esculenta was considered in this correlation, the coefficient decreased to $r^{2}=0.61$. It indicated that some nonphenolic compounds, e.g. polysaccharides, with strong antioxidant activity were probably in the SP extract of $A$. esculenta thus further identification and antioxidant activity test is needed. The correlation between TPC and the antioxidant activity of extracts from both macroalgae and terrestrial plants were reported in the literature. High correlation coefficient $\left(r^{2}=0.99\right)$ was found between TPC and DPPH scavenging activity between SPs of Icelandic seaweeds ${ }^{[4]}$. Total phenols of wild berry fruits grown in southeast Serbia were found to 
correlate negatively with the $\mathrm{IC}_{50}$ values ${ }^{[23]}$. Similar results were also reported in the enzyme-assisted extract from grape residues ${ }^{[24]}$. These studies suggested that polyphenols were the major antioxidants in macroalgae and terrestrial plants.

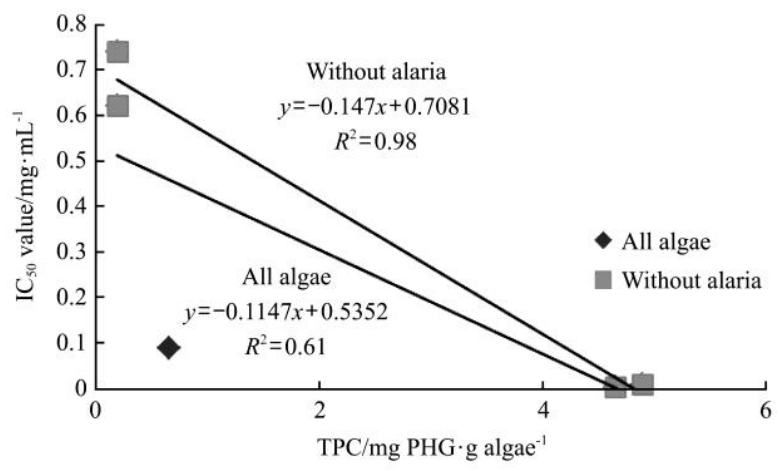

Figure 3 Correlation between $\mathrm{IC}_{50}$ and SP content

The yields of SP extracts are shown in Table 2. The highest yield, 26.34 $\pm 3.54 \mathrm{mg}$-extract/g-algae, was obtained in A. nodosum by Method 2. However, the yield of the same algae by Method 1 was significantly lower at $12.80 \pm 1.37 \mathrm{mg}$-extract/g-algae. Interestingly, $F$. vesiculosus showed no differences in the yield between the two extraction methods. The yields of the other three algae A. esculenta, S. latissima and L. digitata, were significantly lower than A. nodosum and $F$. vesiculosus. Wang et al. ${ }^{[4]}$ reported that the solvents used had an impact on the yield of phenolic compounds from marine macroalgae. They also found that the yield of $S$. Latissima was low because of the high content of alginate in the extracts.

Table 2 Yeld and antioxidant potential of SP extracts by both extraction methods

\begin{tabular}{clcc}
\hline $\begin{array}{c}\text { Extraction } \\
\text { method }\end{array}$ & \multicolumn{1}{c}{ Algae species } & $\begin{array}{c}\text { Yield } \\
\text { /mg-extract·(g-algae) }\end{array}$ & $\begin{array}{c}\text { Antioxidant Potential } \\
/ \text { /mL-DPPH } \\
\text { solution· }(\text { g-algae) }\end{array}$ \\
\hline & Ascophyllum nodosum & $12.80 \pm 1.37 \mathrm{~b}$ & $1777.78 \pm 190.31 \mathrm{~s}$ \\
& Fucus vesiculosus & $14.83 \pm 3.67 \mathrm{~b}$ & $3903.51 \pm 996.04 \mathrm{r}$ \\
Method 1 & Alaria esculenta & $4.10 \pm 0.46 \mathrm{c}$ & $45.56 \pm 5.09 \mathrm{t}$ \\
& Laminaria digitata & $1.78 \pm 0.16 \mathrm{c}$ & $2.41 \pm 0.22 \mathrm{t}$ \\
& Saccharina latissima & $1.83 \pm 0.15 \mathrm{c}$ & $2.96 \pm 0.25 \mathrm{t}$ \\
\hline \multirow{2}{*}{ Method 2 } & Ascophyllum nodosum & $26.34 \pm 3.54 \mathrm{a}$ & $4180.42 \pm 561.96 \mathrm{r}$ \\
& Fucus vesiculosus & $15.25 \pm 1.13 \mathrm{~b}$ & $1980.52 \pm 147.08 \mathrm{~s}$
\end{tabular}

Note: The letters a, b, c and d indicate significant differences among SP yields in the order of $a>b>c>d$ while $r, s$ and $t$ indicate significant differences among the $\mathrm{AP}$ in the order of $\mathrm{r}>\mathrm{s}>\mathrm{t}(p<0.05)$.

The Antiradical Power (ARP), which was $1 / \mathrm{IC}_{50}$, was used in the literature as the parameter evaluating antioxidant activity instead of $\mathrm{IC}_{50}$. Wang et al. ${ }^{[4]}$ found that the ARP of $A$. nodosum and $F$. vesiculosus were higher than that of A. esculenta, L. digitata and $S$. latissima. However, ARP does not reflect the amount of extracts from the source material. In order to evaluate the potential of the brown algae extracts as natural antioxidant sources, a new parameter named Antioxidant Potential (AP), which considered both the yield and antioxidant activity of the extracts was applied to evaluate the potential of brown algae extracts as natural antioxidants.

$$
\mathrm{AP}=\text { yield of extracts } \times \frac{1}{I C_{50}}
$$

As shown in Table 2, the SP extracts of $F$. vesiculosus by Method 1 and $A$. nodosum by Method 2 had the highest AP values of $3903.51 \pm 996 \mathrm{~mL} / \mathrm{g}$ and $4180.42 \pm$ $562 \mathrm{~mL} / \mathrm{g}$ algae, respectively. The AP values of $A$. nodosum and $F$. vesiculosus were much higher than $A$. esculenta, S. latissima and L. digitata, which indicated their greater potential of usage as natural antioxidant sources.

\subsection{DPPH scavenging activity of MP and eMP}

The DPPH scavenging activities of the MP extracts of A. nodosum and $F$. vesiculosus that had the strongest antioxidant activities in their SP extracts are shown in Figure 4. The $\mathrm{IC}_{50}$ values of MP extracts from $A$. nodosum and $F$. vesiculosus by Method 1 were lower than Method 2. The lowest $\mathrm{IC}_{50}$ value, which was $0.0047 \pm$ $0.0002 \mathrm{mg} / \mathrm{mL}$, was observed from $F$. vesiculosus by Method 1. However, the largest $\mathrm{IC}_{50}$ value, 0.0092 \pm $0.0003 \mathrm{mg} / \mathrm{mL}$, was also observed in the same algae by Method 2. It indicated that extraction methods had significant effects on the antioxidant activity of MP extracts. Budhiyanti et al. ${ }^{[8]}$ reported that the $\mathrm{IC}_{50}$ values for scavenging DPPH radicals of membrane bound phlorotannin extracts of Sargassum hystrix were between $0.27 \mathrm{mg} / \mathrm{mL}$ and $3.98 \mathrm{mg} / \mathrm{mL}$, which were larger than BHT. This result indicated that $F$. vesiculosus and $A$. nodosum might be better sources of membrane bound phlorotannin sources than S. hystrix. The algae powder residue of Sargassum micracanthum was treated with methanol and chloroform and the extracts showed better DPPH radical scavenging activity than $\mathrm{BHT}^{[25]}$. These two studies suggested that the algae residue after solvent 
extraction can be good sources of phlorotannins and antioxidants.

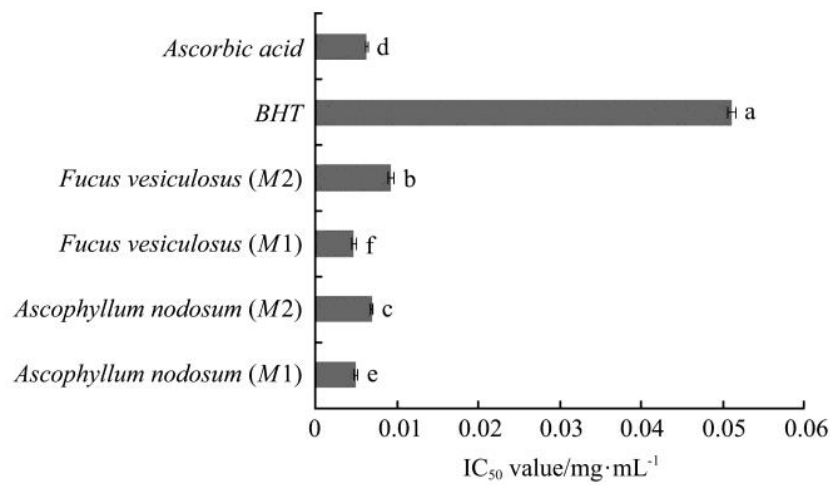

Note: Different letters indicate significant differences $(p<0.05)$ in the order of $\mathrm{a}>\mathrm{b}>\mathrm{c}>\mathrm{d}>\mathrm{e}>\mathrm{f}$. Lower IC50 values mean higher antioxidant activity.

Figure $4 \mathrm{IC}_{50}$ values of the MP extracts (M1-Method 1, M2-Method 2) and commercial antioxidants

The DPPH scavenging activities of the eMP extracts of $A$. nodosum and F. vesiculosus are presented in Figure 5. A. nodosum had stronger antioxidant activity by both extraction methods than $F$. vesiculosus. It suggested that the radical scavenging activity of eMP from $F$. vesiculosus was not as strong as that of A. nodosum. Significant differences between the eMP extracts of $F$. vesiculosus obtained from the two extraction methods also suggested that extraction method had effects on the antioxidant activity of eMP extracts and Method 1 was the better method in terms of $F$. vesiculosus but Method 2 was better for A. nodosum.

Yields and AP values of the MP and eMP extracts of A. nodosum and $F$. vesiculosus are shown in Table 3.
Unlike the DPPH scavenging activity, yields of MP extracts were not very different from each other except for $F$. vesiculosus, whose yield by Method 1 was greater than by Method 2. Similar result was also observed in its eMP yields, with the eMP yield by Method 1 much greater than Method 2. These results suggested that Method 1 was better than Method 2 in terms of phlorotannin yields from $F$. vesiculosus. Surprisingly, the yields of MP and eMP extracts from A. nodosum were not significantly different between the two extraction methods, suggesting that extraction processes had no effects on the yields of MP and eMP of A. nodosum. For every algae and both extraction methods, the AP value of the eMP was lower than that of the MP extract, indicating better potential of MP than eMP as natural antioxidants.

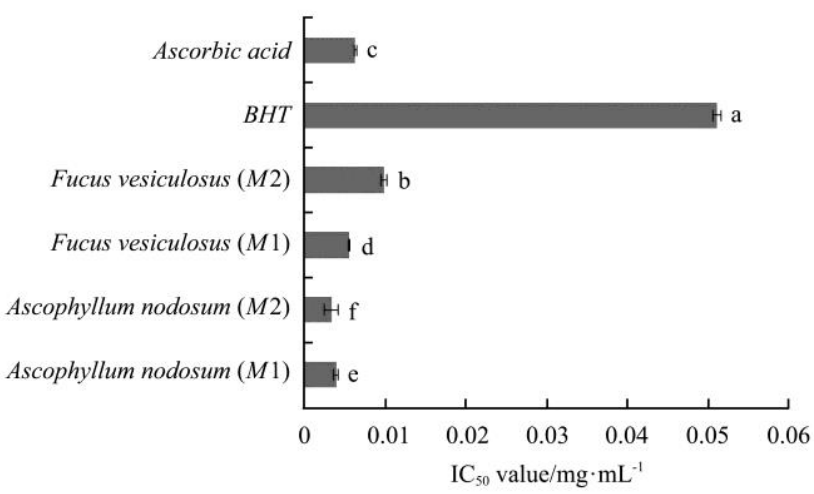

Note: Different letters indicate significant differences $(p<0.05)$ in the order of $\mathrm{a}>\mathrm{b}>\mathrm{c}>\mathrm{d}>\mathrm{e}>\mathrm{f}$. Lower IC50 values mean higher antioxidant activity.

Figure $5 \mathrm{IC}_{50}$ values of the eMP extracts (M1: Method 1, M2: Method 2)

Table 3 Yield and antioxidant potential of MP and eMP extracts

\begin{tabular}{|c|c|c|c|c|c|}
\hline $\begin{array}{l}\text { Extraction } \\
\text { method }\end{array}$ & Algae species & $\begin{array}{c}\text { Yield of MP } \\
/ \mathrm{mg} \text {-extract } \cdot(\mathrm{g} \text {-algae })^{-1}\end{array}$ & $\begin{array}{l}\text { Antioxidant potential of MP } \\
/ \mathrm{mL}-\mathrm{DPPH} \text { solution } \cdot(\mathrm{g} \text {-algae })^{-1}\end{array}$ & $\begin{array}{c}\text { Yield of eMP } \\
/ \mathrm{mg} \text {-extract } \cdot(\mathrm{g} \text {-algae })^{-1}\end{array}$ & $\begin{array}{l}\text { Antioxidant Potential of eMP } \\
/ \mathrm{mL}-\mathrm{DPPH} \text { solution } \cdot(\mathrm{g} \text {-algae })^{-1}\end{array}$ \\
\hline Method 1 & A. nodosum & $26.39 \pm 0.24 \mathrm{ab}$ & $5278.03 \pm 47.82 \mathrm{o}$ & $7.68 \pm 0.50 t$ & $1969.53 \pm 128.73 y$ \\
\hline \multirow{2}{*}{ Method 2} & A. nodosum & $26.03 \pm 0.74 \mathrm{ab}$ & $3772.91 \pm 107.80 \mathrm{p}$ & $7.30 \pm 0.48 \mathrm{t}$ & $2212.21 \pm 144.59 y$ \\
\hline & F. vesiculosus & $25.45 \pm 0.73 b$ & $2766.02 \pm 79.03 q$ & $13.63 \pm 0.74 \mathrm{~s}$ & $1391.23 \pm 75.69 \mathrm{z}$ \\
\hline
\end{tabular}

Note: Different groups of letters, a, b, c, d; o, p, q; r, s, t and x, y, z indicate significant difference ( $p<0.05)$ among yield of MP, AP value of MP, yield of eMP, and AP value of eMP, respectively, in the order of $a>b>c>d, o>p>q, r>s>t$, and $x>y>z$.

\subsection{Comparison of the antioxidant activity among SP, MP and eMP}

The antioxidant activities of the three phlorotannin groups, SP, MP and eMP, are presented in Table 4. In A. nodosum, the eMP extracts showed the strongest antioxidant activity while the SP extracts of $F$. vesiculosus were the strongest antioxidants by both extraction methods. It has been demonstrated in a previous study that high molecular weight phlorotannins had more potent antioxidant activities than the monomers ${ }^{[24]}$. Thus phlorotannins with higher degree of polymerization and higher molecular weight might be in the SP of $F$. vesiculosus and eMP of A. nodosum. It was reported that the membrane bound phlorotannin extracts 
of $S$. hystrix showed stronger DPPH scavenging activities than the cytoplasmic extracts and was probably caused by high molecular weight components in the membrane bound extracts $^{[8]}$. Surprisingly, the antioxidant activity of MP was stronger than eMP for $F$. vesiculosus, indicating that the purification process for obtaining eMP might have removed non-phenolic compounds with strong radical scavenging activities.

Table 4 Comparison of $\mathrm{IC}_{50}$ values among the three phlorotannin groups SP, MP and eMP obtained from the same extraction method and algae species

\begin{tabular}{ccccc}
\hline \multirow{2}{*}{$\begin{array}{c}\text { Phlorotannin } \\
\text { group }\end{array}$} & \multicolumn{2}{c}{ IC $_{50}$ of Method 1} & & \multicolumn{2}{c}{ IC $_{50}$ of Method 2} \\
\cline { 2 - 5 } \cline { 4 - 5 } & Ascophyllum & $\begin{array}{c}\text { Fucus } \\
\text { vesiculosus }\end{array}$ & $\begin{array}{c}\text { Ascophyllum } \\
\text { nodosum }\end{array}$ & $\begin{array}{c}\text { Fucus } \\
\text { vesiculosus }\end{array}$ \\
\hline SP & $* * *$ & $*$ & $* *$ & $*$ \\
MP & $* *$ & $* *$ & $* * *$ & $* *$ \\
eMP & $*$ & $* * *$ & $*$ & $* * *$ \\
\hline
\end{tabular}

Note: Different numbers of ' $*$ ' indicate the significant difference $(p<0.05)$ among the SP, MP, and eMP groups in a column. Fewer '*' indicates smaller IC50 (stronger antioxidant activity) in the column. Comparisons were made among SP, MP and eMP obtained from one algae by one extraction method.

Table 5 shows the AP values of the three phlorotannin groups. MP extracts were the highest among the three phlorotannin groups except for A. nodosum by Method 2 . From this table it can be concluded that the MP was the phlorotannin group with the best potential to be applied as natural antioxidants. Compared with Table 4 it can be found that the phlorotannin group with strong antioxidant property may not be the best source of natural antioxidants when the yield of that phlorotannin is taken into consideration.

Table 5 Comparison of AP values among three phlorotannin groups SP, MP and eMP obtained from the same extraction method and algae species

\begin{tabular}{cccccc}
\hline \multirow{2}{*}{$\begin{array}{c}\text { Phlorotannin } \\
\text { group }\end{array}$} & \multicolumn{2}{c}{ AP of Method 1 } & \multicolumn{2}{c}{ AP of Method 2} \\
\cline { 2 - 5 } \cline { 4 - 5 } & $\begin{array}{c}\text { Ascophyllum } \\
\text { nodosum }\end{array}$ & $\begin{array}{c}\text { Fucus } \\
\text { vesiculosus }\end{array}$ & $\begin{array}{c}\text { Ascophyllum } \\
\text { nodosum }\end{array}$ & $\begin{array}{c}\text { Fucus } \\
\text { vesiculosus }\end{array}$ \\
\hline SP & $*$ & $*$ & $* * *$ & $* *$ \\
MP & $* * *$ & $* * *$ & $* *$ & $* * *$ \\
eMP & $* *$ & $* *$ & $*$ & $*$ \\
\hline
\end{tabular}

Note: Different numbers of ' $*$ ' indicate the significant difference $(p<0.05)$ among the SP, MP, and eMP groups in a column. The AP value with more '*, indicates greater AP in the column. Comparisons were made among SP, MP and eMP obtained from one algae by one extraction method.

\section{Conclusions}

The SP extracts of $A$. nodosum and $F$. vesiculosus showed better antioxidant activity than that of S. latissima,
A. esculenta, and L. digitata, indicating that there existed significant differences in the phlototannin contents among different algae species. The MP extracts showed the highest antioxidant potential among the three phlorotannin groups of SP, MP and eMP, which suggested that obtaining phlorotannins from leftover residue after SP extraction could be worthwhile for isolation of natural antioxidants. The antioxidant activity and yield of phlorotannins were also found to be affected by the solvent extraction methods used. For the two extraction methods studied here, Method 1 was much simpler and less time and solvent consuming, therefore, Method 1 should be considered as the preferred method in commercialization, unless the resultant antioxidant activity and phlorotannins yield from Method 1 are much lower than from Method 2.

\section{Acknowledgements}

This work was financially supported by the start-up fund of North Carolina State University.

\section{[References]}

[1] Chew Y L, Lim Y Y, Omar M, Khoo K S. Antioxidant activity of three edible seaweeds from two areas in South East Asia. Swiss Society of Food Science and Technology, 2008; 41: 1067-1072.

[2] Choi C Y, Jo G H, Lee J I, Seo Y, Han T J, Choi I W, et al. Alaria esculenta extract protects against oxidative damage by inducing heme oxygenase-1 expression via Akt and Nrf2. Mol. Cell. Toxicol, 2009; 5(2): 120-125.

[3] Ahn G N, Kim K N, Cha S H, Song C B, Lee J, Heo M S, et al. Antioxidant activities of phlorotannins purified from Ecklonia cava on free radical scavenging using ESR and $\mathrm{H}_{2} \mathrm{O}_{2}$-mediated DNA damage. Eur. Food. Res. Technol, 2007; 226: 71-79.

[4] Wang T, Jonsdottir R, Olafsdottir G. Total phenolic compounds, radical scavenging and metal chelation of extracts from Icelandic seaweeds. Food Chemistry, 2009; 116, 240-248.

[5] Kim R, Shin T S, Lee M S, Park J Y, Park K E, Yoon N Y, et al. Isolation and identification of phlorotannins from Ecklonia stolonifera with antioxidant and anti-inflammatory properties. Journal of Agricultural and Food Chemistry, 2009; 57: 3483-3489.

[6] Kang S M, Heo S J, Kim K N, Lee S H, Jeon Y J. Isolation and identification of new compound, 
2,7''-phloroglucinol-6,6'-bieckol from brown algae, Ecklonia cava and its antioxidant effect. Journal of Functional Foods, 2012; 4: 158-166.

[7] Eom S H, Kim Y M, Kim S K. Antimicrobial effect of phlorotannins from marine brown algae. Food and Chemical Toxicology, 2012; 50: 3251-3255.

[8] Budhiyanti S A, Raharjo S, Marseno D W, Lelana I Y B. Free radical scavenging, metal chelating and singlet oxygen quenching activity of fractionated brown seaweed Sargassum hystrix extract. Journal of Biological Sciences, 2011; 11(4): 288-298.

[9] Ahn M J, Yoon K D, Min S Y, Lee J S, Kim J H, Kim T G, et al. Inhibition of HIV-1 reverse transcriptase and protease by phlorotannins from the brown alga Ecklonia cava. Biol. Pharm. Bull, 2004; 27(4): 544-547.

[10] Artan M, Li Y, Karadeniz F, Lee S H, Kim M M, Kim S K. Anti-HIV-1 activity of phloroglucinol derivative, 6,6'-bieckol, from Ecklonia cava. Bioorganic \& Medicinal Chemistry, 2008; 16: 7921-7926.

[11] Kang M C, Wijesinghe W A J P, Lee S H, Kang S M, Ko S C, Yang X D, et al. Dieckol isolated from brown seaweed Ecklonia cava attenuates type II diabetes in $\mathrm{db} / \mathrm{db}$ mouse model. Food and Chemical Toxicology, 2013; 53: 294-298.

[12] Eom S H, Kang Y M, Park J H, Yu D U, Jeong E T, Lee M S, et al. Enhancement of polyphenol content and antioxidant activity of brown alga Eisenia bicyclis extract by microbial fermentation. Fisheries and Aquatic Sciences, 2011; 14(3): 192-197.

[13] Kim T H, Bae J S. Ecklonia cava extracts inhibit lipopolysaccharide induced inflammatory responses in human endothelial cells. Food and Chemical Toxicology, 2010; 48: 1682-1687.

[14] Nakai M, Kageyama N, Nakahara K, Miki W. Phlorotannins as radical scavengers from the extract of Sargassum ringgoldianum. Marine Biotechnology, 2006; 8: 409-414.

[15] Iwai K. Antidiabetic and antioxidant effects of polyphenols in brown alga Ecklonia stolonifera in genetically diabetic KK-Ay mice. Plant Foods Hum Nutr, 2008; 63: 163-169.

[16] Prior R L, Wu X L, Schaich K. Standardized methods for the determination of antioxidant capacity and phenolics in foods and dietary supplements. Journal of Agricultural and Food Chemistry, 2005; 53: 4290-4302.

[17] Rajauria G, Jaiswal A K, Abu-Gannam N, Gupta S. Antimicrobial, antioxidant and free radical-scavenging capacity of brown seaweed Himanthalia elongata from western coast of Ireland. Journal of Food Biochemistry, 2013; 37: 322-335.

[18] Dawidowica A J, Wianowska D, Olszowy M. On practical problems in estimation of antioxidant activity of compounds by DPPH. method (Problems in estimation of antioxidant activity. Food Chemistry, 2012; 131: 1037-1043.

[19] Villano D, Fernandez-Pachon M S, Moya M L, Troncoso A M, Garcia-Parrilla M C. Radical scavenging ability of polyphenolic compounds towards DPPH free radical. Talanta, 2007; 71: 230-235.

[20] Cox S, Abu-Ghannam N, Gupta S. An assessment of the antioxidant and antimicrobial activity of six species of edible Irish seaweeds. International Food Research Journal, 2010; 17: 205-220.

[21] Turkmen N, Velioglu Y S, Sari F, Polat G. Effect of extraction conditions on measured total polyphenol contents and antioxidant and antibacterial activities of black tea. Molecules, 2007; 12: 484-496.

[22] Chandini S K, Ganesan P, Bhaskar N. In vitro antioxidant activities of three selected brown seaweeds of India. Food Chemistry, 2008; 107: 707-713.

[23] Radovanovic B C, Andelkovic A S M, Radovanovic A B, Andelkovic M Z. Antioxidant and antimicrobial activity of polyphenol extracts from wild berry fruits grown in southeast Serbia. Tropical Journal of Pharmaceutical Research, 2013; 12(5): 813-819.

[24] Gomez-Garcia R, Martinez-Avila G C G, Aguilar C N. Enzyme-assisted extraction of antioxidative phenolics from grape (Vitis vinifera L.) residues. 3 Biotech, 2012; 2: 297-300.

[25] Mori J, Matsunaga T, Takahashi S, Hasegawa C, Saito H. Inhibitory activity on lipid peroxidation of extracts from marine brown alga. Phytotherapy Research, 2003; 17: $549-551$. 